\title{
Geraniin protects bone marrow-derived mesenchymal stem cells against hydrogen peroxide-induced cellular oxidative stress in vitro
}

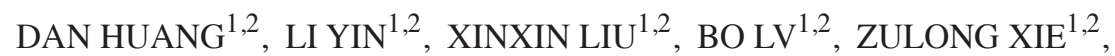 \\ XUEDONG WANG ${ }^{1,2}$, BO YU ${ }^{1,2}$ and YAO $\mathrm{ZHANG}^{1}$ \\ ${ }^{1}$ Department of Cardiology, The Second Affiliated Hospital of Harbin Medical University; \\ ${ }^{2}$ The Key Laboratory of Myocardial Ischemia, Harbin Medical University, \\ Ministry of Education, Harbin, Heilongjiang 150001, P.R. China
}

Received August 18, 2016; Accepted November 8, 2017

DOI: 10.3892/ijmm.2017.3276

\begin{abstract}
Administration of bone marrow-derived mesenchymal stem cells (MSCs) has emerged as a potential therapeutic approach for the treatment of myocardial infarction (MI). However, the increase in reactive oxygen species (ROS) in ischemic cardiac tissue compromises the survival of transplanted MSCs, thus resulting in limited therapeutic efficiency. Therefore, strategies that attenuate oxidative stress-induced damage and enhance MSC viability are required. Geraniin has been reported to possess potent antioxidative activity and exert protective effects on numerous cell types under certain conditions. Therefore, geraniin may be considered a potential drug used to modulate MSC-based therapy for MI. In the present study, MSCs were pretreated with geraniin for $24 \mathrm{~h}$ and were exposed to hydrogen peroxide $\left(\mathrm{H}_{2} \mathrm{O}_{2}\right)$ for $4 \mathrm{~h}$. Cell apoptosis, intracellular ROS levels and mitochondrial membrane potential were measured using Annexin V-fluorescein isothiocyanate/ propidium iodide staining, the 2',7'-dichlorodihydrofluorescein diacetate fluorescent probe and the membrane permeable dye JC-1, respectively. Glutathione and malondialdehyde levels were also investigated. The expression levels of apoptosis-associated proteins and proteins of the phosphoinositide 3-kinase $(\mathrm{PI} 3 \mathrm{~K})$ /protein kinase B (Akt) signaling pathway were analyzed by western blotting. The results demonstrated that geraniin could significantly attenuate $\mathrm{H}_{2} \mathrm{O}_{2}$-induced cell damage by promoting MSC survival, reducing cellular ROS production and maintaining mitochondrial function. Furthermore, geraniin modulated the expression levels of phosphorylated-Akt in a time- and dose-dependent manner. The cytoprotective
\end{abstract}

Correspondence to: Dr Yao Zhang, Department of Cardiology, The Second Affiliated Hospital of Harbin Medical University, 148 Baojian Road, Harbin, Heilongjiang 150001, P.R. China E-mail: yaozhang_grace@163.com

Key words: geraniin, mesenchymal stem cells, hydrogen peroxide, oxidative stress, phosphoinositide 3-kinase/protein kinase B signaling pathway effects of geraniin were suppressed by LY294002, a specific PI3K inhibitor. In conclusion, the present study revealed that geraniin protects MSCs from $\mathrm{H}_{2} \mathrm{O}_{2}$-induced oxidative stress injury via the PI3K/Akt pathway. These findings indicated that cotreatment of MSCs with geraniin may optimize therapeutic efficacy for the clinical treatment of MI.

\section{Introduction}

Myocardial infarction (MI) is among the main causes of mortality worldwide (1). Irreversible loss of cardiac myocytes and concomitant cicatrization are induced by MI; therefore, patients exhibit poor cardiac pump function and congestive heart failure. Cell-based therapy for MI represents an emerging strategy in biological therapeutics $(2,3)$. As one of the most frequently investigated cellular populations, bone marrow-derived mesenchymal stem cells (MSCs) are particularly attractive therapeutic candidates. MSC-based therapy relies on the self-renewal capability of MSCs, and the ability of MSCs to differentiate into cardiovascular cells and secrete multitudinous bioactive molecules. These actions subsequently activate endogenous neovascularization, immunomodulation and cardiac regeneration, thus resulting in restoration of cardiac function (4). However, current evidence indicates that poor viability of engrafted MSCs in the infarcted myocardium is a primary limitation of the therapeutic efficacy of MSCs $(5,6)$. Reactive oxygen species (ROS), including hydrogen peroxide $\left(\mathrm{H}_{2} \mathrm{O}_{2}\right)$, superoxide radicals and hydroxyl radicals, are produced during infarction (7) or reperfusion of ischemic hearts (8). ROS may lead to impaired cell metabolism and decreased cell viability, thus inhibiting transplanted MSCs from taking effect. Therefore, protecting MSCs from apoptosis, together with enhancing their ability to survive under oxidative stress, is crucial for optimizing MSC-based therapy.

Polyphenols, or polyphenolic compounds, are widely distributed in natural plants, and range from simple structures, such as flavonoids, to highly complex polymeric substances, including proanthocyanidins and ellagitannins (9). Due to their various biological activities, polyphenols exhibit potential as effective therapeutic drugs. In addition, they have 
been demonstrated to display numerous pharmacological activities, including anticarcinogenic (10), antibacterial (11) and antidiabetic (12) effects. Furthermore, polyphenols are strong antioxidants, due to their free radical-scavenging activities (13). Geraniin is a typical ellagitannin, which has been identified as the major active compound extracted from Geranium sibiricum. A previous study reported that geraniin possesses marked nitric oxide-scavenging, superoxide radical-scavenging and $\beta$-carotene-linoleic acid-bleaching properties due to its unique chemical structure (Fig. 1A) (14). Furthermore, geraniin has been confirmed to protect liver cells against ethanol-induced cytotoxicity (15) and inhibit apoptosis of pulmonary fibroblasts under $\gamma$-radiation conditions (16). Our previous study demonstrated that geraniin may exert strong ROS-scavenging activities when preventing THP-1 macrophages from switching to an M1 phenotype under lipopolysaccharide stimulation (17). Since $\mathrm{H}_{2} \mathrm{O}_{2}$ is often used in vitro to simulate the oxidative stress microenvironment detected in ischemic heart tissue, the present study hypothesized that geraniin may defend MSCs against $\mathrm{H}_{2} \mathrm{O}_{2}$-induced damage. The present study aimed to investigate the cytoprotective effects of geraniin on MSCs against $\mathrm{H}_{2} \mathrm{O}_{2}$-induced cellular injury, as well as the underlying mechanism.

\section{Materials and methods}

Materials. Geraniin (purity $\geq 98 \%$ ) was purchased from Shanghai Yuanye Bio-Technology Co., Ltd. (Shanghai, China), and was dissolved in dimethyl sulfoxide (DMSO) and stored at $-80^{\circ} \mathrm{C}$. The stock concentration of geraniin was $10 \mathrm{mM}$. DMSO and $\mathrm{H}_{2} \mathrm{O}_{2}$ were purchased from Sigma-Aldrich (Merck KGaA, Darmstadt, Germany). Dulbecco's modified Eagle's medium (DMEM)/F12 and fetal bovine serum (FBS) were obtained from Gibco (Thermo Fisher Scientific, Inc., Waltham, MA, USA). The conjugated antibodies used to identify MSCs: Fluorescein isothiocyanate (FITC)-labeled anti-CD29 (555005) and anti-CD44 (561859), and phycoerythrin-labeled anti-CD45 (553091) and anti-CD90 (551401), as well as the Annexin V-FITC/propidium iodide (PI) apoptosis detection kit, were all purchased from BD Biosciences (Franklin Lakes, NJ, USA). Cell Counting kit-8 (CCK-8) was from Dojindo Molecular Technologies, Inc. (Kumamoto, Japan). Hoechst 33342, JC-1 dye, 2',7'-dichlorodihydrofluorescein diacetate (DCFH-DA) fluorescent probe, glutathione (GSH) kit (S0053), malondialdehyde (MDA) kit (S0131), ROS scavenger N-acetyl-L-cysteine (NAC), cell mitochondrial protein isolation kit (C3601), radioimmunoprecipitation assay (RIPA) lysis buffer, bicinchoninic acid (BCA) protein assay kit and mouse polyclonal anti- $\beta$-actin (AA128) were all purchased from Beyotime Institute of Biotechnology (Beijing, China). Rabbit antibodies against phosphorylated-protein kinase B [p-Akt (Ser473); 4060s], Akt (9272s), caspase-3 (9662s), B-cell lymphoma 2 (Bcl-2; 2876s), Bcl-2-associated X protein (Bax; 2772s) and cytochrome $c$ (Cyt $C$; 4272s), and LY294002 [phosphoinositide 3-kinase (PI3K) specific inhibitor], were all purchased from Cell Signaling Technology, Inc. (Danvers, MA, USA). Horseradish peroxidase (HRP)-conjugated anti-rabbit (ZB-2301) and anti-mouse (ZB-2305) secondary antibodies were obtained from OriGene Technologies, Inc., (Beijing, China).
MSCs isolation and culture. MSCs were isolated and harvested from male Sprague-Dawley rats (age, 3 weeks old; weight, 60-80 g), as previously described with minor modifications (18). A total of 10 SPF Sprague-Dawley rats were purchased from the Laboratory Animal Science Department of the Second Affiliated Hospital of Harbin Medical University (Harbin, China). They were kept under standard animal housing conditions (temperature, $21 \pm 1^{\circ} \mathrm{C}$; humidity, $55 \pm 5 \%$ ), at a 12 -h dark/light cycle and had access to unlimited food and water. The present study was approved by the Local Ethics Committee on Animal Care and Use of Harbin Medical University. Briefly, total bone marrow was flushed from the tibias and femurs of the rats with $10 \mathrm{ml}$ DMEM/F12 using a sterile syringe. After centrifugation at $300 \mathrm{x} g$ for $5 \mathrm{~min}$, the remaining pellets were resuspended in $5 \mathrm{ml} \mathrm{DMEM} / \mathrm{F} 12$ supplemented with $10 \%$ FBS and $1 \%$ penicillin/streptomycin, and were then seeded into cell culture flasks at $37^{\circ} \mathrm{C}$ in an atmosphere containing $5 \% \mathrm{CO}_{2}$. Following incubation for $48 \mathrm{~h}$, the culture medium and non-adherent cells were discarded and fresh medium was added. The medium was replaced every $72 \mathrm{~h}$ thereafter. Cells were cultured until they reached $80 \%$ confluence, after which they were passaged. Cells were split using $0.25 \%$ trypsin and were expanded at a $1: 2$ or $1: 3$ dilution. Cells from passages 3-5 were used in the subsequent experiments. The MSC population was characterized according to positive (CD44, CD29 and CD90) and negative (CD45) cell surface markers by flow cytometry, as reported in our previous studies $(18,19)$.

Cell treatments. All treatments were conducted at $37^{\circ} \mathrm{C}$ in the incubator. MSCs were seeded into six-well plates or a $25 \mathrm{~cm}^{2}$ culture flask. Once cell density reached $60-70 \%, \mathrm{H}_{2} \mathrm{O}_{2}(100$, 200, 300, 400 and $500 \mu \mathrm{M}$ ), mixed with serum-free DMEM/ F12 for $4 \mathrm{~h}$, was used to establish an in vitro oxidative stress model. Geraniin, at $1,5,10$ and $20 \mu \mathrm{M}$, was separately preincubated in DMEM/F12 for $24 \mathrm{~h}$. The inhibitor of PI3K, LY294002 $(25 \mu \mathrm{M})$, or the ROS scavenger, NAC (500 $\mu \mathrm{M})$, was added $1 \mathrm{~h}$ prior to $\mathrm{H}_{2} \mathrm{O}_{2}$ treatment without geraniin co-treatment. Cells cultured in complete medium without any specific treatment comprised the control group.

Cell viability assay. MSC viability was assessed using the CCK-8 assay. Briefly, cells were plated into 96-well plates $\left(3 \times 10^{3}\right.$ cells/well). Following cell adhesion to the plates, appropriate treatments were administered. Subsequently, the medium was removed and replaced with $100 \mu 1$ fresh DMEM/F12 and $10 \mu \mathrm{l}$ CCK-8 solution in each well. The plates were maintained at $37^{\circ} \mathrm{C}$ for $1 \mathrm{~h}$. Finally, absorbance was detected at $450 \mathrm{~nm}$ using a Tecan Infinite 200 PRO microplate reader (Tecan Austria GmbH, Grödig, Austria).

Measurement of cell apoptosis. Apoptosis of MSCs was determined using the Annexin V-FITC/PI staining method. Following treatment, the cells were harvested, washed with ice-cold PBS and resuspended in $400 \mu \mathrm{l}$ binding buffer. The cell suspension was then incubated with $5 \mu$ l Annexin V solution for $15 \mathrm{~min}$ at room temperature in the dark, followed by incubation with $5 \mu \mathrm{l}$ PI for an additional $5 \mathrm{~min}$. The cells were immediately analyzed by flow cytometry using BD FACSCanto II (BD Biosciences). Approximately $1 \times 10^{5}$ cells were detected in each sample. According to the 
A

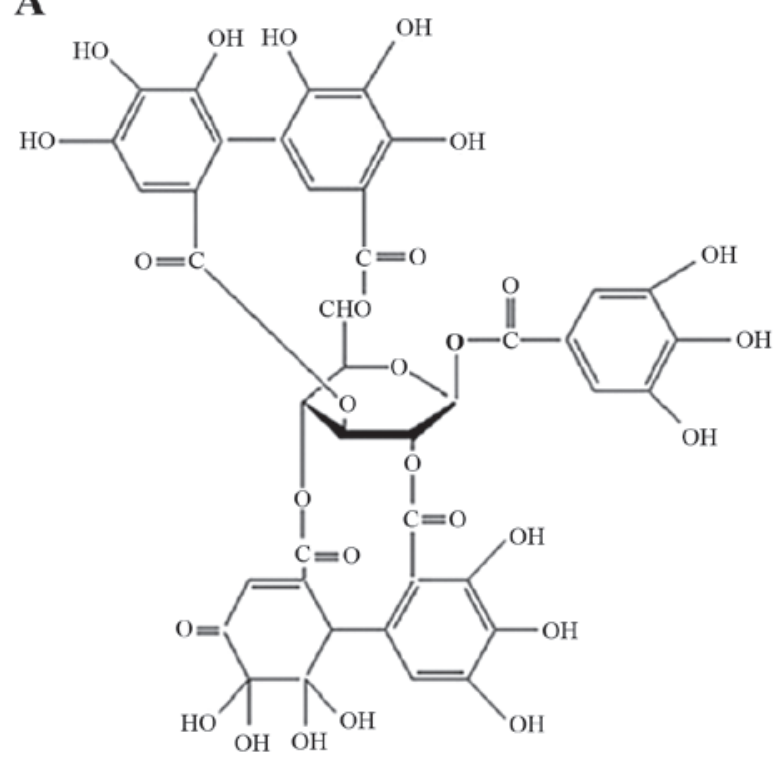

B

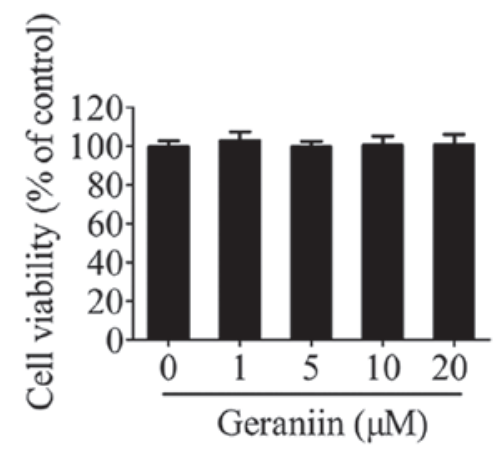

Figure 1. Chemical structure of geraniin and effects of geraniin on MSC viability. (A) Chemical structure of geraniin. (B) MSCs were treated with various concentrations of geraniin for $24 \mathrm{~h}$, and viability was measured using the Cell Counting kit- 8 assay. Data are presented as the mean \pm standard deviation from five replicate wells and are representative of three independent experiments. MSCs, mesenchymal stem cells.

reaction principles, Annexin $\mathrm{V}^{-} / \mathrm{PI}^{-}$staining signified viable cells, Annexin $\mathrm{V}^{+} / \mathrm{PI}^{-}$indicated early apoptotic cells, and Annexin $\mathrm{V}^{+} / \mathrm{PI}^{+}$represented late apoptotic or necrotic cells.

Assessment of morphological alterations. MSCs were treated with geraniin and $\mathrm{H}_{2} \mathrm{O}_{2}$ in six-well plates. Hoechst 33342 was used to detect cell nuclear condensation and fragmentation. After fixing in $4 \%$ paraformaldehyde for $15 \mathrm{~min}$ at room temperature, cells were washed twice with PBS, stained with $5 \mu \mathrm{g} / \mathrm{ml}$ Hoechst 33342 for 5 min and washed a further two times with PBS. Finally, cells were assessed by fluorescence microscopy. Apoptotic cells were identified by condensed or fragmented nuclei.

ROS, GSH and MDA assays. Intracellular ROS levels were determined using a ROS assay kit. Briefly, cells were incubated with the diluted fluorescent probe, DCFH-DA, for $20 \mathrm{~min}$ at $37^{\circ} \mathrm{C}$. Cells were then washed three times with serum-free DMEM/F12, collected and analyzed using a flow cytometer. Due to the important roles of GSH and MDA in ROS-associated oxidative stress, their concentrations were also measured using commercial kits according to the manufacturer's protocols.

Detection of mitochondrial membrane potential $\left(\Psi_{m}\right)$. JC-1 was used to measure alterations in $\Psi \mathrm{m}$. Briefly, cells were washed with PBS, stained with $5 \mu \mathrm{M}$ JC-1 and maintained for $20 \mathrm{~min}$ at $37^{\circ} \mathrm{C}$. Subsequently, cells were washed twice with ice-cold JC-1 staining buffer and were then directly observed under a fluorescence microscope, or were collected and analyzed by flow cytometry.

Protein extraction and western blot analysis. Cells were washed with ice-cold PBS, lysed with RIPA lysis buffer and centrifuged at $12,000 \mathrm{x}$ g for $15 \mathrm{~min}$ at $4^{\circ} \mathrm{C}$. The extraction of cytoplasmic and mitochondrial proteins was conducted in accordance with the manufacturer's protocol. BCA protein assay was used to quantify protein concentrations. Equal amounts of total protein $(50 \mu \mathrm{g} /$ lane) were separated by $8-12 \%$ SDS-PAGE and were transferred onto polyvinylidene fluoride membranes. The membranes were blocked with $5 \%$ skim milk diluted in Tris-buffered saline containing $0.05 \%$ Tween-20 (TBST) at $37^{\circ} \mathrm{C}$ for $1 \mathrm{~h}$, and were then incubated with diluted primary antibodies against p-Akt (S473) (1:1,000), total-Akt $(1: 1,000)$, cleaved caspase-3 (1:1,000), Bax (1:1,000), Bcl-2 (1:1,000), Cyt $C(1: 1,000)$ and $\beta$-actin $(1: 800)$ overnight at $4^{\circ} \mathrm{C}$. After washing three times with TBST, membranes were incubated with the corresponding HRP-conjugated secondary antibodies $(1: 5,000)$ for $1 \mathrm{~h}$ at room temperature. The images of the immune complexes were developed by ECL in the dark, and images were captured using a Tanon-5200 (Tanon Science and Technology Co., Ltd., Shanghai, China). Band density was determined using ImageJ $(1.48 \mathrm{u}$; National Institutes of Health, Bethesda, MD, USA).

Statistical analysis. All data are presented as the mean \pm standard deviation and were analyzed using SPSS 19.0 software (IBM Corp., Armonk, NY, USA). Differences between groups were analyzed by one-way ANOVA with a Tukey's post hoc test. $\mathrm{P}<0.05$ was considered to indicate a statistically significant difference.

\section{Results}

Effects of geraniin on MSC viability. Initially, the effects of geraniin on MSC viability were examined using the CCK-8 assay. Treatment with geraniin for $24 \mathrm{~h}$ had little influence on cell viability compared with the $0 \mu \mathrm{M}$ geraniin group (Fig. 1B). This result indicated that geraniin did not exert toxic effects on MSCs.

Geraniin significantly inhibits $\mathrm{H}_{2} \mathrm{O}_{2}$-induced apoptosis of MSCs. $\mathrm{H}_{2} \mathrm{O}_{2}$ has been reported to induce apoptosis of MSCs at various concentrations and time-points $(20,21)$. To establish a successful in vitro oxidative stress model, the present 
A

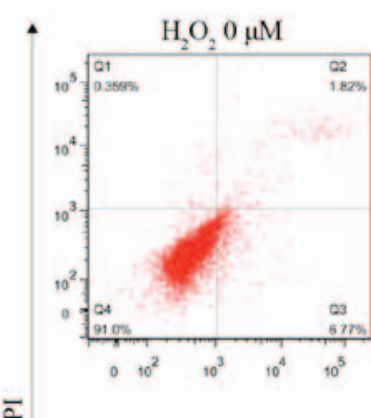

$\bar{a}$

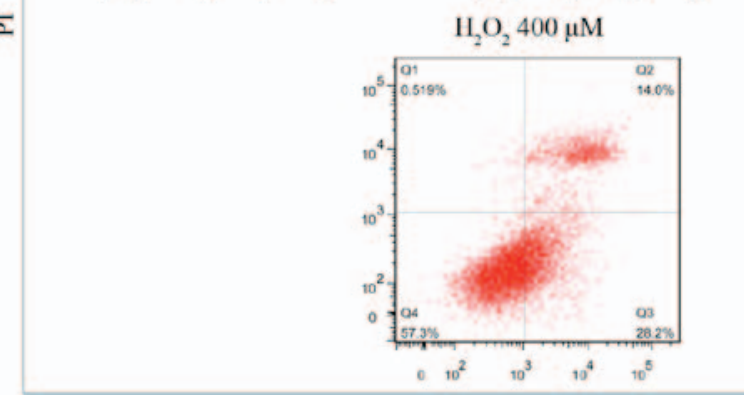

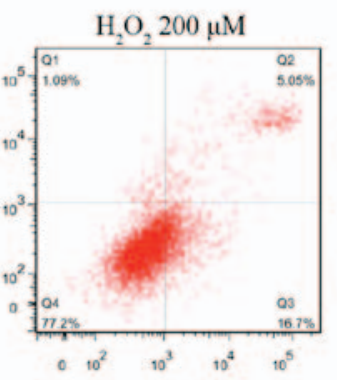
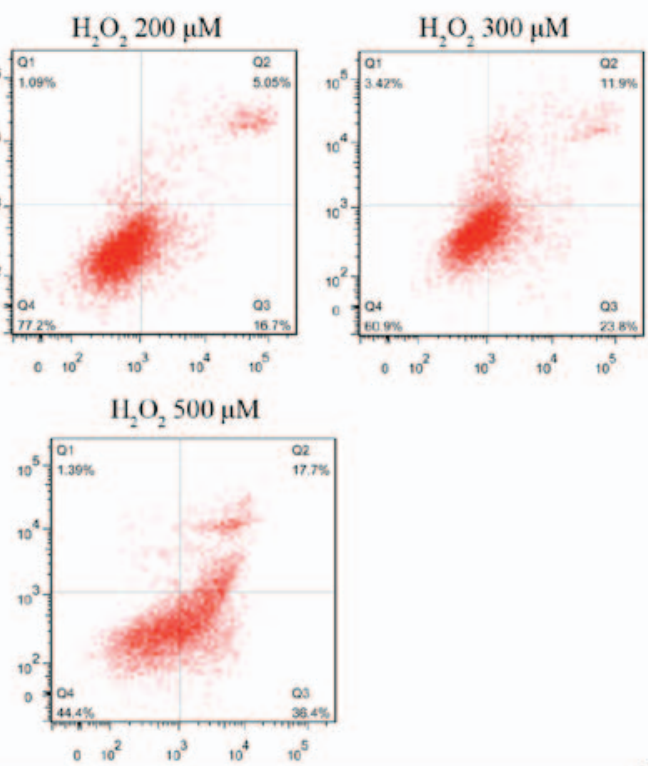

Annexin V-FITC

B

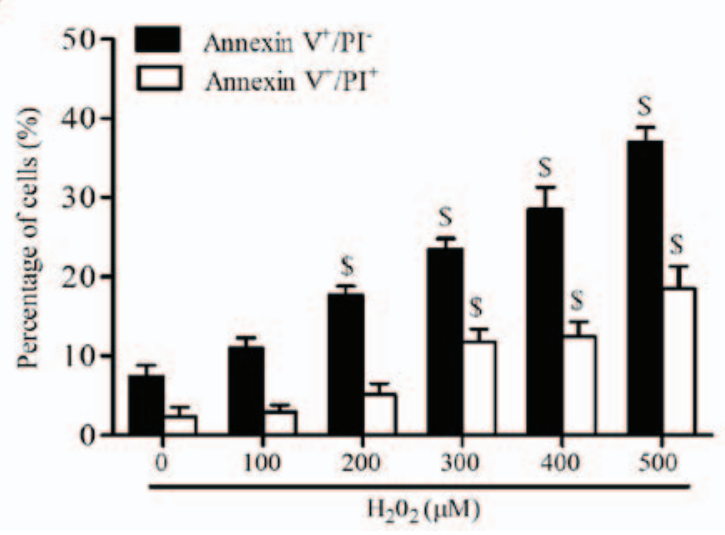

C

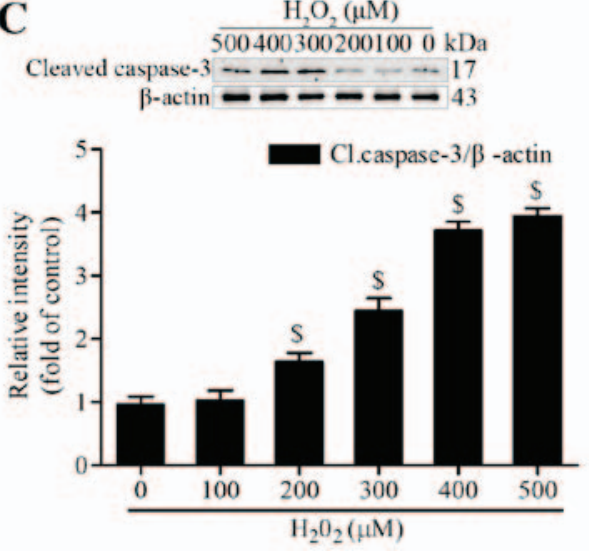

Figure 2. $\mathrm{H}_{2} \mathrm{O}_{2}$ induces apoptosis of MSCs. (A and B) Cells were treated with a range of $\mathrm{H}_{2} \mathrm{O}_{2}$ concentrations for 4 h, and apoptosis was analyzed by Annexin V-FITC/PI staining assay. (C) $\mathrm{H}_{2} \mathrm{O}_{2}$-induced cleaved caspase-3 expression was measured by western blotting, $\beta$-actin was used for normalization. Data are presented as the mean \pm standard deviation of three independent measurements. ${ }^{\$} \mathrm{P}<0.05$ compared with the $0 \mu \mathrm{M} \mathrm{H} \mathrm{H}_{2} \mathrm{O}_{2}$ group. Cl.caspase-3, cleaved caspase-3; FITC, fluorescein isothiocyanate; $\mathrm{H}_{2} \mathrm{O}_{2}$, hydrogen peroxide; MSCs, mesenchymal stem cells; PI, propidium iodide.

study investigated the proapoptotic effects of $\mathrm{H}_{2} \mathrm{O}_{2}$ on MSCs. Following treatment with various concentrations of $\mathrm{H}_{2} \mathrm{O}_{2}$ $(100-500 \mu \mathrm{M})$ in serum-free medium for $4 \mathrm{~h}$, MSCs were stained with Annexin V-FITC/PI. The proportion of early apoptotic cells (Annexin $\mathrm{V}^{+} / \mathrm{PI}$ ) was significantly increased following treatment with $\geq 200 \mu \mathrm{M} \mathrm{H}_{2} \mathrm{O}_{2}$, whereas the proportion of late apoptotic or necrotic MSCs (Annexin $\mathrm{V}^{+} / \mathrm{PI}^{+}$) was markedly increased following treatment with $\geq 300 \mu \mathrm{M}$ (Fig. 2A and B). In addition, the expression levels of cleaved caspase- 3 were significantly increased at $200 \mu \mathrm{M}$ and continued to increase to $500 \mu \mathrm{M}$ (Fig. 2C). We then selected treatment with $\mathrm{H}_{2} \mathrm{O}_{2}$ at $300 \mu \mathrm{M}$ for $4 \mathrm{~h}$ as the condition to induce effective apoptosis, since this concentration generated moderate apoptotic cells.

To determine whether geraniin rescues MSCs from $\mathrm{H}_{2} \mathrm{O}_{2}$-induced apoptosis, MSCs were pretreated with increasing concentrations of geraniin $(1,5,10$ and $20 \mu \mathrm{M})$ for $24 \mathrm{~h}$. MSCs were then co-treated with geraniin and $\mathrm{H}_{2} \mathrm{O}_{2}$. A significant reversal in the percentage of $\mathrm{H}_{2} \mathrm{O}_{2}$-induced Annexin $\mathrm{V}^{+} / \mathrm{PI}$ cells, in response to geraniin, was observed by flow cytometry (geraniin $1 \mu \mathrm{M}, 20.53 \pm 1.25 \% ; 5 \mu \mathrm{M}, 18.67 \pm 1.89 \% ; 10 \mu \mathrm{M}$, $11.57 \pm 1.01 \% ; 20 \mu \mathrm{M}, 7.23 \pm 0.31 \% ; \mathrm{P}<0.05$ vs. $\mathrm{H}_{2} \mathrm{O}_{2}$, $23.83 \pm 1.32 \%$ ) (Fig. $3 \mathrm{~A}$ and B). However, $1 \mu \mathrm{M}$ geraniin had no effect on the proportion of Annexin $\mathrm{V}^{+} / \mathrm{PI}^{+}$cells, whereas the other concentrations significantly reduced the percentage of late apoptotic or necrotic cells (geraniin $5 \mu \mathrm{M}, 7.88 \pm 2.58 \%$; $10 \mu \mathrm{M}, 7.05 \pm 1.72 \% ; 20 \mu \mathrm{M}, 4.40 \pm 0.48 \% ; \mathrm{P}<0.05$ vs. $\mathrm{H}_{2} \mathrm{O}_{2}$, $12.97 \pm 1.65 \%$ ) (Fig. 3A and B). Furthermore, in apoptotic cells, nuclei become condensed or fragmented, whereas in normal cells, nuclei are circular or oval. Hoechst 33342 staining was used to confirm the presence of nuclear morphological alterations. Cells treated with $\mathrm{H}_{2} \mathrm{O}_{2}$ appeared to possess shrunken and fragmented nuclei; however, those pretreated with geraniin exhibited marked amelioration of $\mathrm{H}_{2} \mathrm{O}_{2}$-induced nuclear impairment. These data indicated that geraniin may effectively attenuate $\mathrm{H}_{2} \mathrm{O}_{2}$-induced MSC apoptosis (Fig. 3C).

Geraniin exerts protective effects by regulating ROS generation. Since ROS serves a pivotal role in proapoptotic signaling 

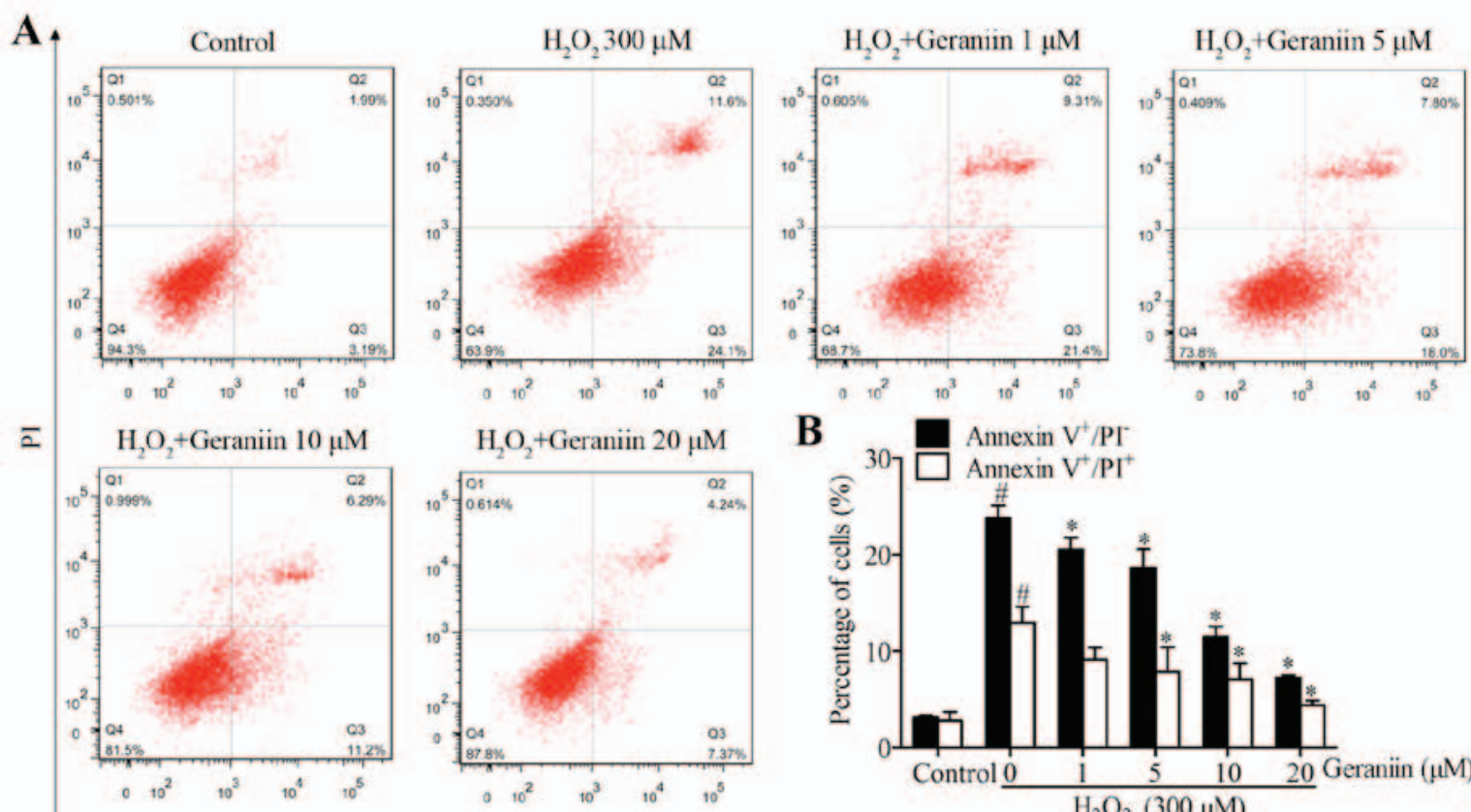

B

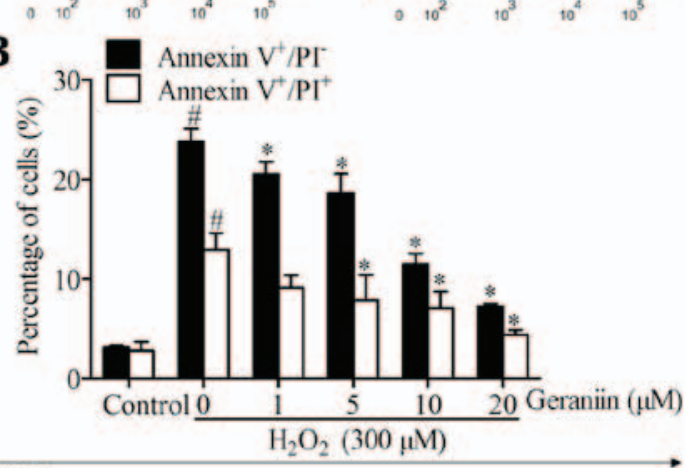

Annexin V-FITC
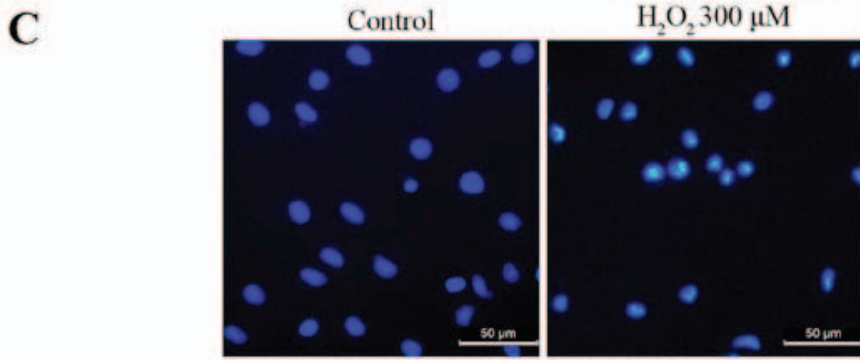

$\mathrm{H}_{2} \mathrm{O}_{2}+\mathrm{Geraniin} 1 \mu \mathrm{M}$
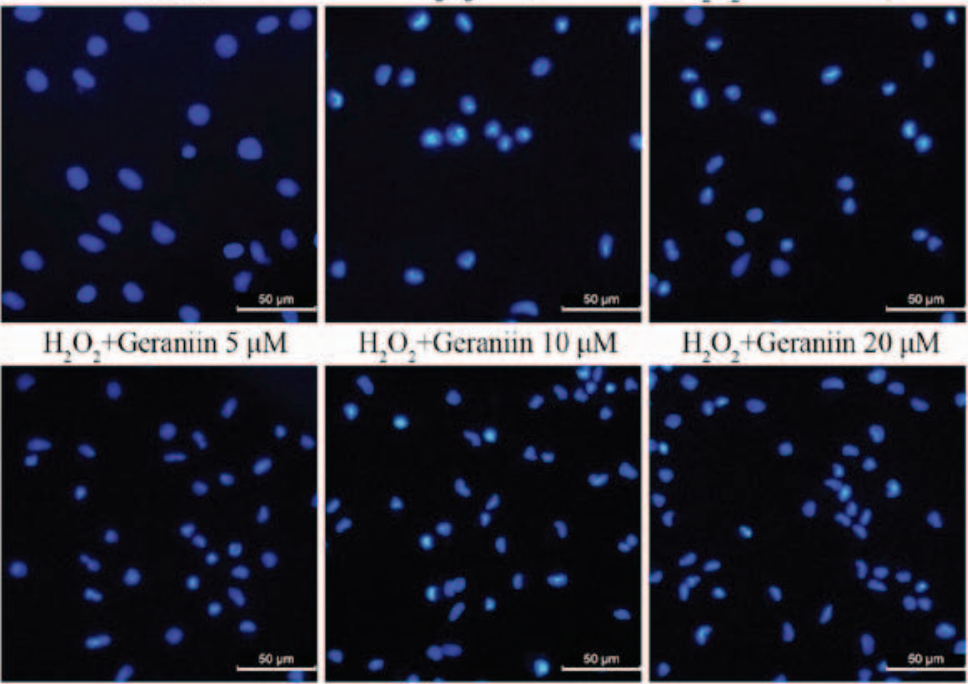

Figure 3. Geraniin reduces $\mathrm{H}_{2} \mathrm{O}_{2}$-induced MSC apoptosis. MSCs were treated with increasing concentrations of geraniin for $24 \mathrm{~h}$ and were then exposed to $300 \mu \mathrm{M} \mathrm{H}_{2} \mathrm{O}_{2}$ for $4 \mathrm{~h}$. Apoptosis was reduced by geraniin in a dose-dependent manner, as identified by (A and B) flow cytometry and (C) Hoechst 33342 staining (original magnification, 200x; scale bar, $50 \mu \mathrm{m}$ ). ${ }^{\prime \prime} \mathrm{P}<0.05$ compared with the control group; ${ }^{*} \mathrm{P}<0.05$ compared with the $300 \mu \mathrm{M} \mathrm{H}_{2} \mathrm{O}_{2}$ group. FITC, fluorescein isothiocyanate; $\mathrm{H}_{2} \mathrm{O}_{2}$, hydrogen peroxide; MSCs, mesenchymal stem cells PI, propidium iodide.

cascades (22), the present study examined the effects of geraniin on ROS generation using flow cytometry. The results demonstrated that $\mathrm{H}_{2} \mathrm{O}_{2}$ induced a 7.6-fold increase in ROS production compared with the control group. However, pretreatment with geraniin markedly suppressed ROS generation in a concentration-dependent manner (Fig. 4A and B). Following treatment with NAC, a general ROS scavenger, similar results were recorded compared with $20 \mu \mathrm{M}$ geraniin (mean fluorescence intensity: Geraniin $20 \mu \mathrm{M}, 476.33 \pm 46.65$; NAC, 443.80 \pm 53.15 , $\mathrm{P}>0.05$ ) (Fig. 4B). Furthermore, alterations in intracellular GSH and MDA contents were investigated; cells pretreated with geraniin had significantly increased GSH levels, whereas MDA production was suppressed by geraniin (Fig. 4C and D). These findings indicated that geraniin is able to enhance the cellular antioxidant system and remove redundant ROS.
Geraniin protects MSCs against oxidative stress through stabilizing the $\Psi m$. Mitochondria in eukaryotic cells are the primary components of respiration, and are critical in the defense against oxidative stress-induced damage (23). Maintaining the $\Psi \mathrm{m}$ is essential to ensure the scavenging efficiency of ROS, and to prevent cell apoptosis or other stress-associated events induced by excessive ROS (24). JC-1 is a $\Psi \mathrm{m}$-sensitive dye, which aggregates in the mitochondrial matrix and exhibits red fluorescence in normal cells. However, when the $\Psi \mathrm{m}$ is reduced, JC-1 is converted to its monomer state, which exhibits green fluorescence. $\mathrm{H}_{2} \mathrm{O}_{2}$ resulted in a marked reduction in $\Psi_{\mathrm{m}}$ within MSCs, whereas geraniin markedly upregulated the $\Psi \mathrm{m}$, as identified by fluorescence microscopy (Fig. 5A). In addition, the ratio of red/green fluorescence intensity was significantly downregulated under $\mathrm{H}_{2} \mathrm{O}_{2}$ 

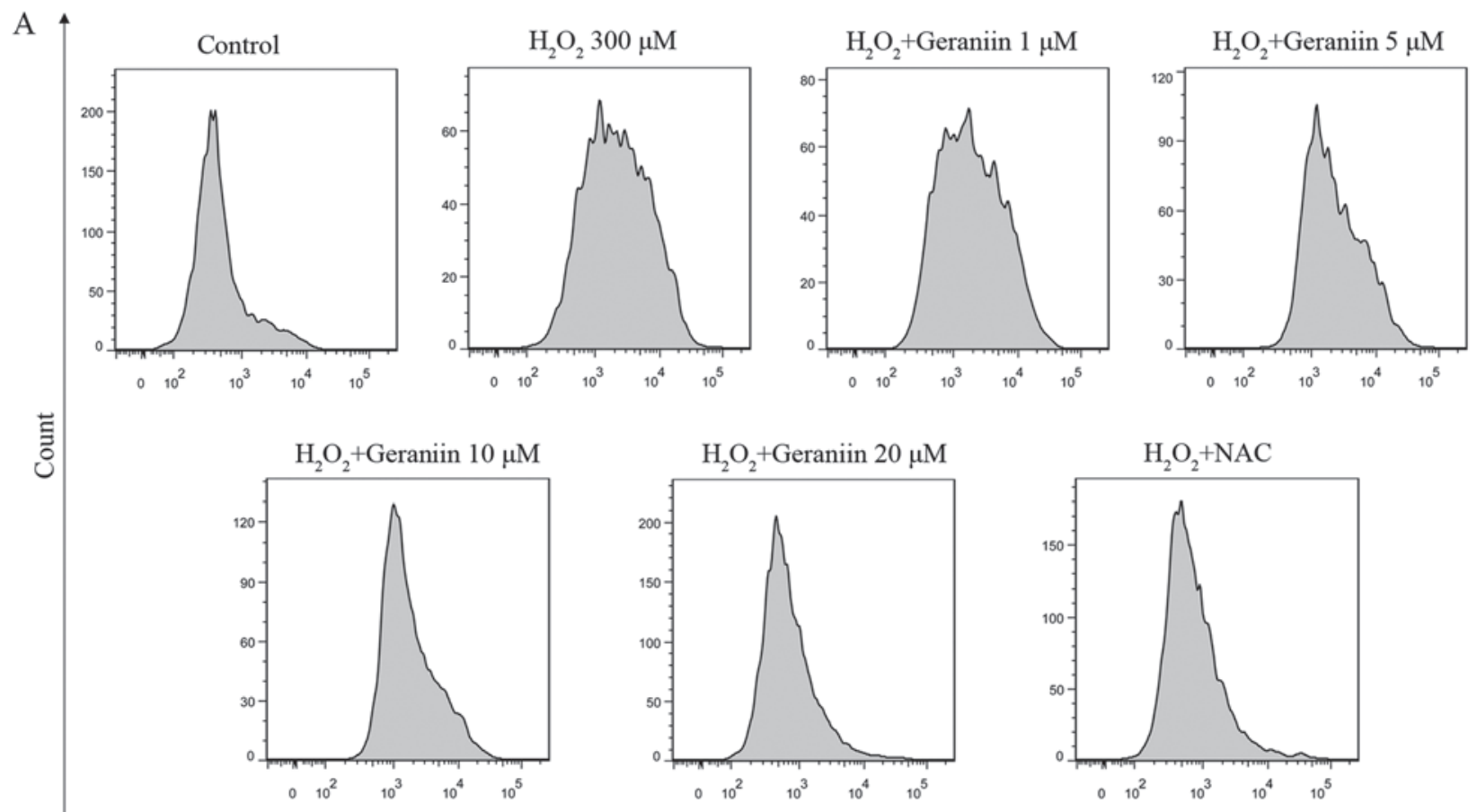

Fluroscence intensity
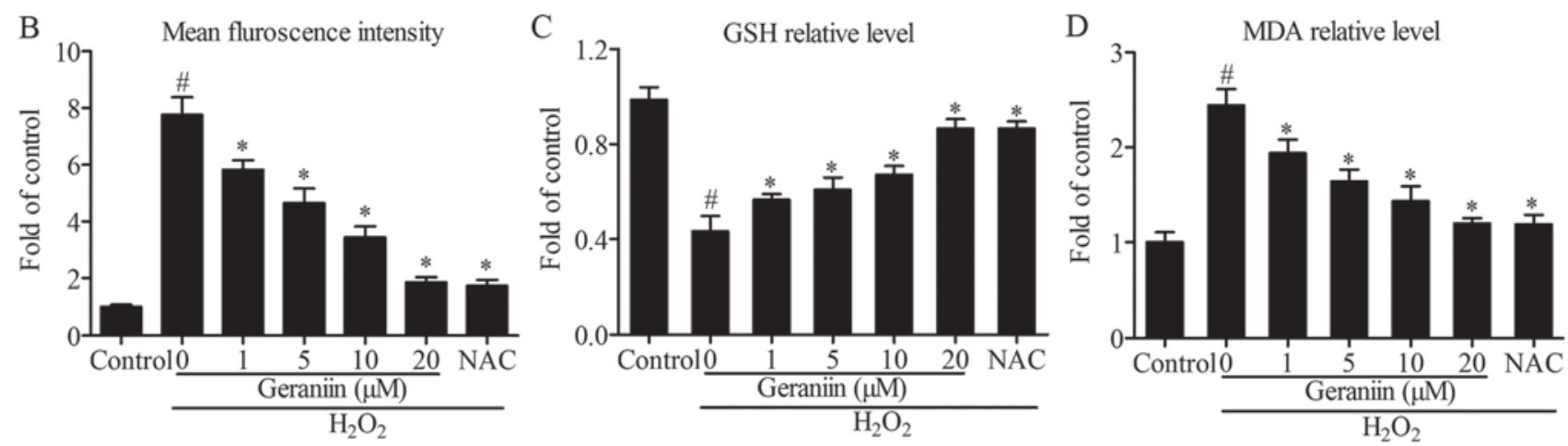

Figure 4. Geraniin exerts protective effects by regulating ROS generation. MSCs were pretreated with the indicated concentrations of geraniin for $24 \mathrm{~h}$ or NAC for $1 \mathrm{~h}$, followed by exposure to $\mathrm{H}_{2} \mathrm{O}_{2}$ for $4 \mathrm{~h}$. (A) Intracellular ROS levels were evaluated by flow cytometry and (B) data were quantified. Alterations in (C) GSH and (D) MDA levels were measured. Data are presented as the mean \pm standard deviation of three independent experiments. ${ }^{*} \mathrm{P}<0.05$ compared with the control group; " $\mathrm{P}<0.05$ compared with the $\mathrm{H}_{2} \mathrm{O}_{2}$-treated group. $\mathrm{GSH}$, glutathione; $\mathrm{H}_{2} \mathrm{O}_{2}$, hydrogen peroxide; MDA, malondialdehyde; MSCs, mesenchymal stem cells; NAC, N-acetyl-L-cysteine; ROS, reactive oxygen species.

exposure compared with in the control group; however, this effect was reversed by geraniin in a concentration-dependent manner (Fig. 5B and C). These findings suggested that geraniin may exert beneficial effects on mitochondrial function.

\section{PI3K/Akt signaling is required for geraniin to exert anti-apop-} totic effects on MSCs. It has previously been reported that geraniin exerts cytoprotective effects on HepG2 cells via activation of the extracellular signal-regulated kinase $1 / 2$ and PI3K/Akt pathways (25). Due to the importance of the PI3K/Akt pathway on classical survival signals (26), the present study aimed to determine the association between geraniin and the PI3K/Akt pathway in MSCs. Cells were treated with geraniin $(20 \mu \mathrm{M})$ for the indicated periods of time; the protein expression levels of p-Akt (Ser473) were transiently upregulated at $15 \mathrm{~min}$ and peaked at $60 \mathrm{~min}$, prior to subsequent downregulation (Fig. 6A). In addition, the effects of $1 \mathrm{~h}$ treatment with various concentrations of geraniin on p-Akt (Ser473) expression in MSCs was investigated; p-Akt expression was upregulated in a dose-dependent manner. Conversely, p-Akt expression was markedly inhibited following pretreatment with LY294002, a PI3K-specific inhibitor (Fig. 6B). These findings indicated that geraniin may activate the PI3K/Akt signaling pathway in a time- and dose-dependent manner.

To gain further insight into the role of the PI3K/Akt pathway in the protective effects of geraniin on MSCs, cells were preconditioned with LY294002 and were then exposed to $20 \mu \mathrm{M}$ geraniin and $\mathrm{H}_{2} \mathrm{O}_{2}$. PI3K inhibition significantly attenuated the anti-apoptotic effects of geraniin on MSCs under $\mathrm{H}_{2} \mathrm{O}_{2}$ treatment, as evidenced by a decrease in cell survival rate using CCK-8 assay (Fig. 6C). Since reductions in the $\Psi \mathrm{m}$ and increased cleaved caspase- 3 expression are initiating and amplifying factors of the mitochondrial apoptosis pathway, it may be suggested that $\mathrm{H}_{2} \mathrm{O}_{2}$ induces apoptosis of MSCs through regulating the mitochondrial apoptosis pathway. Therefore, the expression levels of Cyt $C$, cleaved caspase-3, Bax and Bcl-2 
A

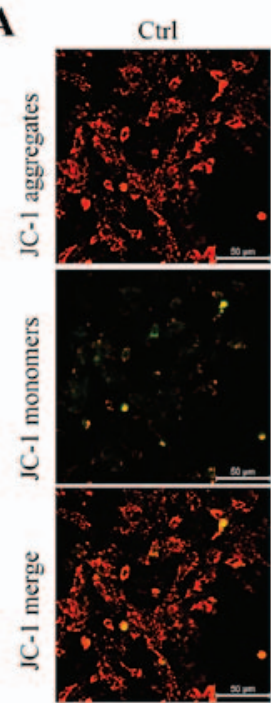

$\mathrm{H}, \mathrm{O}, 300 \mu \mathrm{M}$
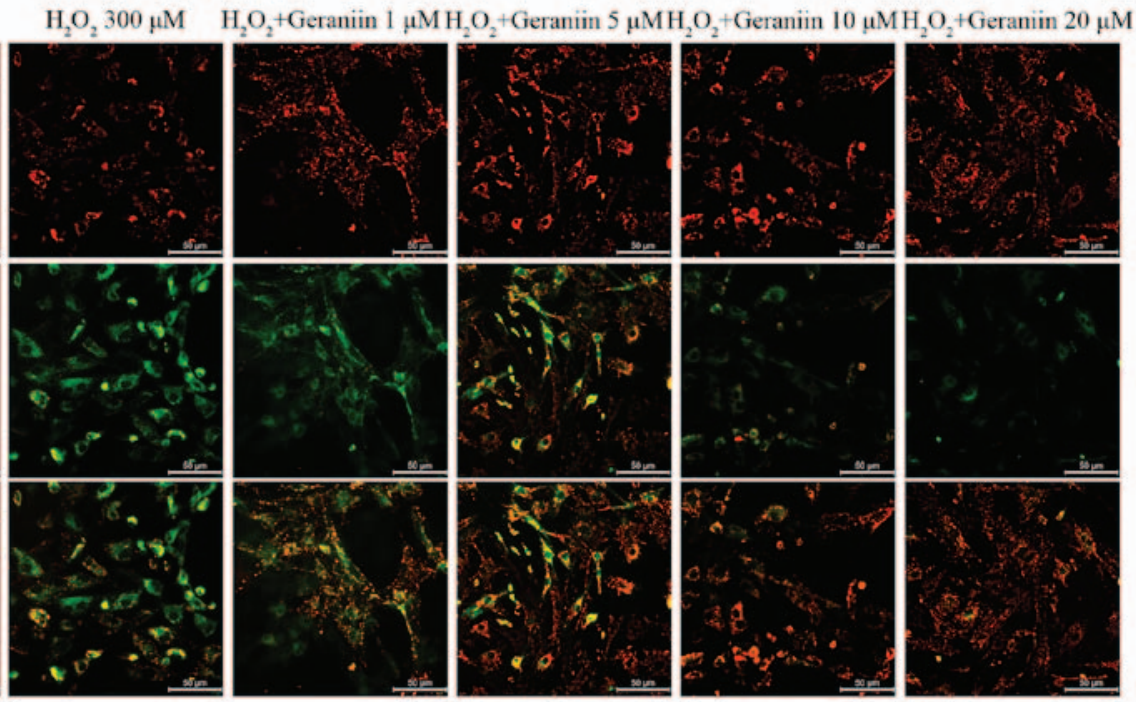

B
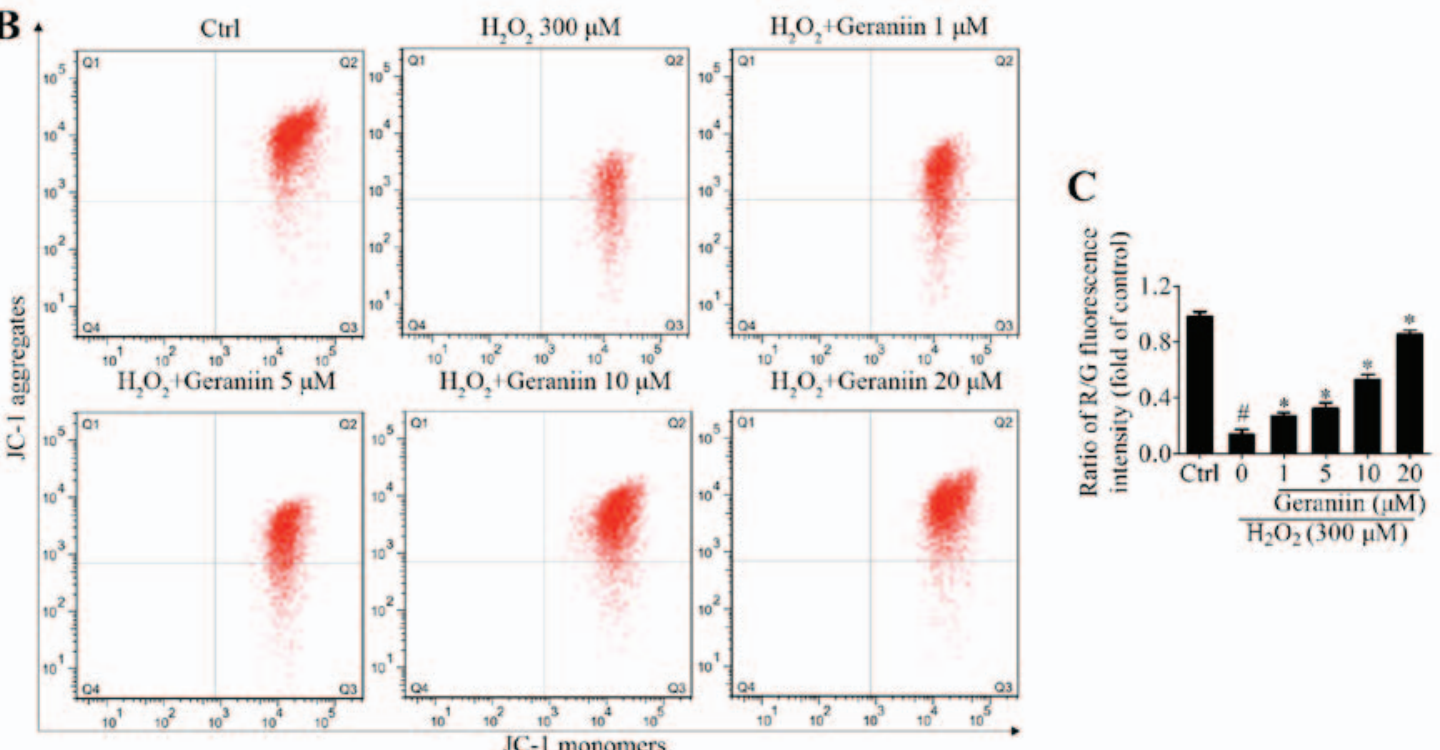

Figure 5. Geraniin protects MSCs against oxidative stress through stabilizing the $\Psi \mathrm{m}$. MSCs were treated with the indicated concentrations of geraniin for $24 \mathrm{~h}$, followed by $\mathrm{H}_{2} \mathrm{O}_{2}$ administration for $4 \mathrm{~h}$. Alterations in $\Psi \mathrm{m}$ were analyzed by (A) fluorescence microscopy (original magnification, $\mathrm{x} 200$; scale bar, $50 \mu \mathrm{m}$ ) and (B) flow cytometry using the JC-1 staining method. (C) Ratio of R/G fluorescence intensity was quantified. Data are presented as the mean \pm standard deviation of three separate experiments. ${ }^{~} \mathrm{P}<0.05$ compared with the control group; ${ }^{*} \mathrm{P}<0.05$ compared with the $\mathrm{H}_{2} \mathrm{O}_{2}$-treated group. $\Psi \mathrm{m}$, mitochondrial membrane potential; Ctrl, control; $\mathrm{H}_{2} \mathrm{O}_{2}$, hydrogen peroxide; MSCs, mesenchymal stem cells; $\mathrm{R} / \mathrm{G}$, red/green.

were investigated. Treatment with geraniin induced a marked increase in the expression levels of mitochondrial Cyt $C$ and $\mathrm{Bcl}-2$, and a decrease in the expression levels of cytoplasmic Cyt $C$, cleaved caspase-3 and Bax (Fig. 6D-F). These effects were reversed by LY294002. These data indicated that the PI3K/Akt signaling pathway may contribute to the prosurvival role of geraniin in MSCs under $\mathrm{H}_{2} \mathrm{O}_{2}$ treatment.

\section{Discussion}

The present study demonstrated that geraniin could attenuate $\mathrm{H}_{2} \mathrm{O}_{2}$-induced cell damage through promoting MSC survival, reducing cellular ROS production and maintaining mitochondrial function. Furthermore, the effects of geraniin were mediated by activating the PI3K/Akt signaling pathway. Conversely, inhibition of the PI3K/Akt pathway weakened the protective effects of geraniin. To the best of our knowledge, the present study is the first to report the cytoprotective effects of geraniin on MSCs and reveal the underlying mechanism.

MSCs are easily isolated and expanded, and can be transplanted in the heart; therefore, they are considered leading candidates for cellular therapy (27). Substantial data from preclinical and clinical studies support the cardioprotective effects of MSCs. Amado et al demonstrated that, following MSC implantation into swine, reappearance of myocardial tissue and restoration of cardiac contractility could be detected using serial computed tomography imaging (28). Furthermore, the POSEIDON randomized trial demonstrated that intravenous administration of allogeneic MSCs within 7 days of acute MI markedly attenuated cardiac hypertrophy, reduced ventricular arrhythmia, improved heart function and decreased rehospitalization for cardiac complications (27). However, the practical 
A
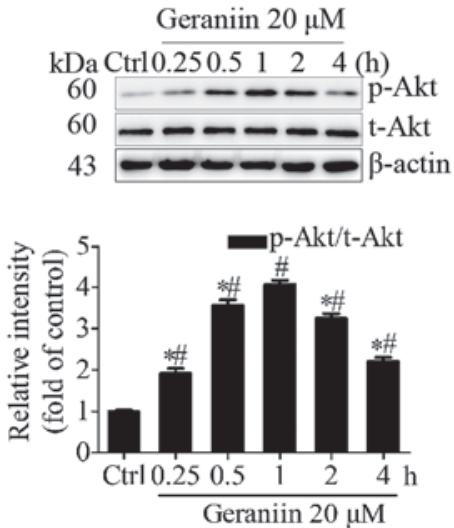

$\mathrm{D}$

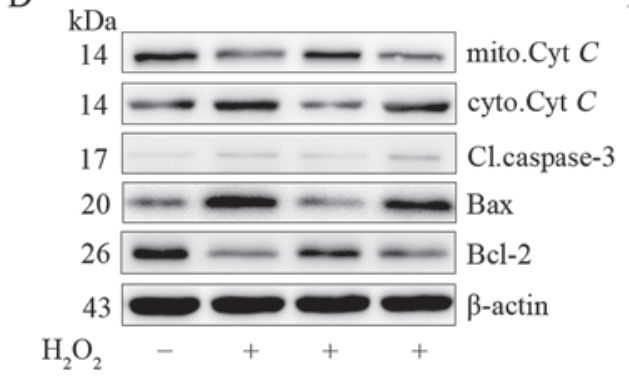

Geraniin

LY294002
B
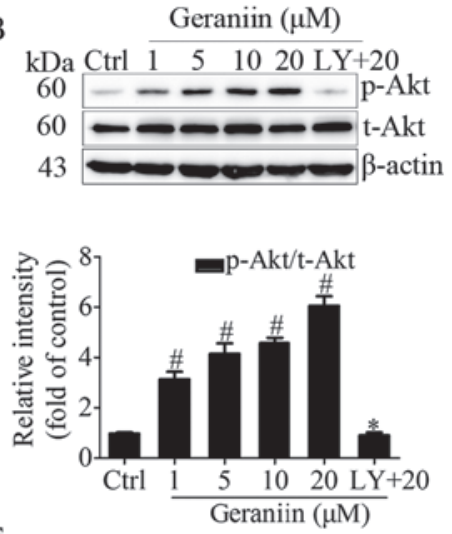

$\mathrm{E}$

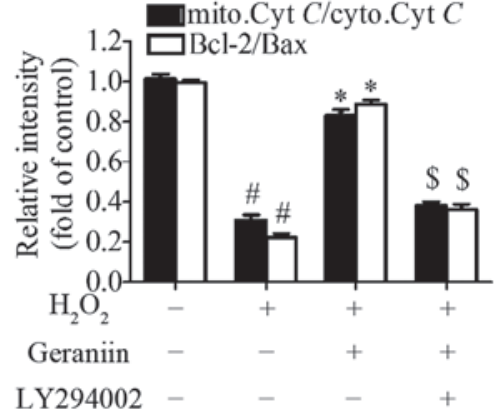

$\mathrm{C}$

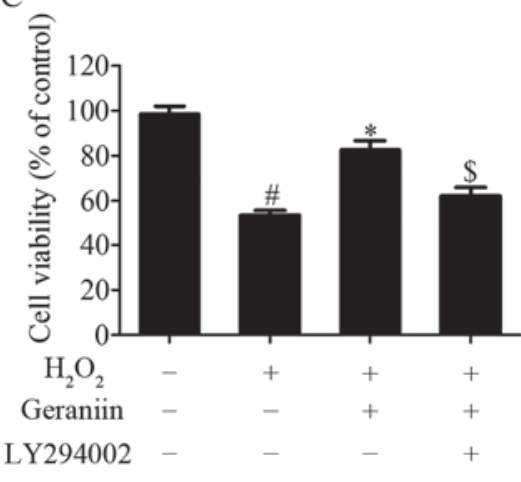

$\mathrm{F}$

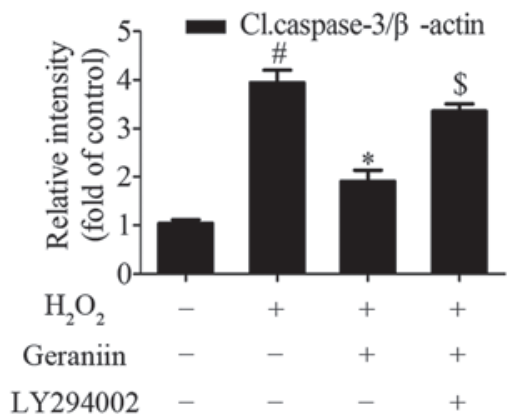

Figure 6. PI3K/Akt signaling is involved in the anti-apoptotic effects of geraniin on MSCs. (A) Cells were treated with geraniin (20 $\mu \mathrm{M})$ for the indicated time-periods or (B) with the indicated concentrations of geraniin for $1 \mathrm{~h}$. The expression levels of p-Akt were evaluated by western blotting. (C) Cells were pretreated with LY294002, and were then incubated with geraniin and $\mathrm{H}_{2} \mathrm{O}_{2}$; cell viability was measured using the Cell Counting kit-8 assay. Expression levels of proteins associated with the mitochondrial apoptosis pathway were assessed (D) by western blotting and (E and F) data were semi-quantified. Data are presented as the mean \pm standard deviation of three independent experiments. ${ }^{\#} \mathrm{P}<0.05$ compared with the control group; ${ }^{*} \mathrm{P}<0.05$ compared with the group treated with $20 \mu \mathrm{M}$ geraniin for $1 \mathrm{~h}(\mathrm{~A}$ and $\mathrm{B})$; ${ }^{*} \mathrm{P}<0.05$ compared with the $\mathrm{H}_{2} \mathrm{O}_{2}$ group $(\mathrm{C}-\mathrm{F})$; ${ }^{\$} \mathrm{P}<0.05$ compared with the geraniin $+\mathrm{H}_{2} \mathrm{O}_{2}$ group. Akt, protein kinase B; Bax, Bcl-2-associated X protein; Bcl-2, B-cell lymphoma 2; Cl.caspase-3, cleaved caspase-3; ctrl, control; cyto.Cyt $C$, cytoplasmic cytochrome $c$; $\mathrm{H}_{2} \mathrm{O}_{2}$, hydrogen peroxide; LY, LY294002; mito.Cyt $C$, mitochondrial cytochrome $c$; p-, phosphorylated; t-, total.

applications of MSCs are restricted by their poor survival rate. A previous study indicated that after 4 days, only $0.44 \%$ of engrafted MSCs survived and resided in the myocardium (29). This low survival rate is mainly due to the hostile microenvironment in injured heart tissue, and ROS burst in the infarcted region is the major risk factor (30). As one of the most stable ROS, $\mathrm{H}_{2} \mathrm{O}_{2}$ is often used to establish an in vitro oxidative stress model for studies regarding apoptosis-associated mechanisms (31). In the present study, treatment with $300 \mu \mathrm{M} \mathrm{H}_{2} \mathrm{O}_{2}$ for $4 \mathrm{~h}$ markedly increased apoptosis of MSCs, thus indicating that exogenous ROS burst results in the critical inducement of transplanted MSC apoptosis. In addition, this result reflects the necessity to identify novel methods to enhance MSC survival upon oxidative stress injury.

Pharmacological studies have confirmed that polyphenols are efficacious in treating ischemic heart diseases. Polyphenols extracted from grapes and wine have been reported to increase coronary flow in vivo (32). Epigallocatechin gallate, which is the major polyphenolic compound in green tea, has been revealed to prevent oxidative stress-induced cardiomyocyte apoptosis in vitro (33). In addition, emerging evidence demonstrated that the mechanism of action of polyphenols is predominantly ascribed to their strong free radical-scavenging activity. Polyphenols are rich in hydroxyl groups, which can capture free radicals and inactivate ROS (34). There are numerous hydroxyl groups within geraniin, indicating its strong antioxidant activity. Therefore, the present study detected the antioxidative effects of geraniin on MSCs exposed to $\mathrm{H}_{2} \mathrm{O}_{2}$; the results confirmed that geraniin pretreatment may reduce excessive cellular ROS levels and preserve mitochondrial function, which may contribute to inhibiting $\mathrm{H}_{2} \mathrm{O}_{2}$-induced apoptosis. Furthermore, cells can defend themselves against oxidative stress through specific scavenging mechanisms, in which GSH and MDA are vital participants. GSH is an important intracellular antioxidative mediator that interacts with redundant ROS and balances cellular oxidation status. MDA is the end product of cellular lipid peroxidation in response to ROS damage. The severity of oxidative injury is, to some degree, reflected by cellular GSH and MDA levels. In the present study, geraniin was able to restore GSH levels, and decrease the amount of MDA, thus suggesting that geraniin functions through enhancing the intrinsic antioxidant repair system to inhibit ROS production and prevent accumulation of intracellular oxidative damage. Furthermore, reduced $\Psi_{\mathrm{m}}$ indicates severe mitochondrial respiratory chain dysfunction and increased generation of ROS, which enhances oxidative stress and activates caspase family-mediated mitochondrial apoptosis (35). The present study indicated that geraniin treatment increases Bcl-2 expression, and decreases the expression levels of Bax and cleaved caspase-3, thus suggesting that geraniin may act on $\Psi \mathrm{m}$ stabilization. In addition, in normal cells, Cyt $C$ is located in the mitochondrial inner membrane and works as an electron transmitter. Numerous proapoptotic stimuli, including ROS, increase permeability of 
the outer membrane and promote mobilization of Cyt $C$ from the mitochondria to the cytosol. In the cytosol, Cyt $C$ mediates maturation of the caspase family, including caspase-3, which ultimately induce cell death (36). In the present study, geraniin treatment inhibited the release of Cyt $C$ from the mitochondria to the cytosol, which indirectly indicated that geraniin preserved mitochondrial membrane integrity. Taken together, these results revealed that geraniin improved MSC viability under oxidative stress by enhancing the ability of the antioxidant defense system to remove excessive ROS, maintaining mitochondrial function and inhibiting the mitochondrial apoptosis pathway.

The PI3K/Akt pathway has been reported to serve an important role in the biological behavior of MSCs in vitro and in MSC engraftment for ischemic treatment in vivo. A previous study confirmed that cell survival, proliferation and migration were enhanced when the PI3K/Akt pathway was activated in MSCs (21). In addition, transplantation of MSCs overexpressing Akt preserved normal cardiac metabolism and $\mathrm{pH}$ post-MI (37). In the present study, the results verified that geraniin could activate the PI3K/Akt signaling pathway, whereas PI3K inhibition abolished the effects of geraniin on MSCs. However, inhibiting PI3K using LY294002 could not absolutely abrogate the protective effects of geraniin, thus suggesting that other pathways may be involved in the actions of geraniin. Numerous studies have indicated that geraniin activates the PI3K/Akt and mitogen-activated protein kinase (MAPK) pathways $(25,38)$. Whether MAPK or other pathways also contribute to the beneficial effects of geraniin requires further study. Furthermore, the stromal cell-derived factor $1 / \mathrm{C}-\mathrm{X}-\mathrm{C}$ chemokine receptor type 4 (CXCR4) axis serves a vital role in mobilization and recruitment of MSCs to the infarcted area (39). PI3K/Akt activation has also been demonstrated to induce an increase in CXCR4 expression in MSCs (40). Whether geraniin may promote CXCR4 expression via the PI3K/Akt pathway remains unknown and requires further research.

In conclusion, the present study provided preliminary evidence to suggest that geraniin exerts prosurvival effects on MSCs against $\mathrm{H}_{2} \mathrm{O}_{2}$-induced cellular oxidative stress, predominantly by activating the PI3K/Akt signaling pathway. These findings indicated that geraniin may be considered a potential drug to enhance MSC-based therapeutic efficacy for the future treatment of MI.

\section{Acknowledgements}

The present study was supported by grants from the National Natural Science Foundation of China (grant no. 30800233 to Y.Z.; grant no. 81330033 to B.Y.).

\section{References}

1. Murray CJ, Vos T, Lozano R, Naghavi M, Flaxman AD Michaud C, Ezzati M, Shibuya K, Salomon JA, Abdalla S, et al: Disability-adjusted life years (DALYs) for 291 diseases and injuries in 21 regions, 1990-2010: A systematic analysis for the Global Burden of Disease Study 2010. Lancet 380: 2197-2223, 2012.

2. Ripa RS, Haack-Sørensen M, Wang Y, Jørgensen E, Mortensen S, Bindslev L, Friis T and Kastrup J: Bone marrow derived mesenchymal cell mobilization by granulocyte-colony stimulating factor after acute myocardial infarction: Results from the Stem Cells in Myocardial Infarction (STEMMI) trial. Circulation 116 (Suppl 11): I24-I30, 2007.
3. Zhang Z, Liang D, Gao X, Zhao C, Qin X, Xu Y, Su T, Sun D, Li W, Wang H, et al: Selective inhibition of inositol hexakisphosphate kinases (IP6Ks) enhances mesenchymal stem cell engraftment and improves therapeutic efficacy for myocardial infarction. Basic Res Cardiol 109: 417, 2014.

4. Karantalis V and Hare JM: Use of mesenchymal stem cells for therapy of cardiac disease. Circ Res 116: 1413-1430, 2015.

5. Fisher SA, Zhang H, Doree C, Mathur A and Martin-Rendon E: Stem cell treatment for acute myocardial infarction. Cochrane Database Syst Rev 9: CD006536, 2015.

6. Geng YJ: Molecular mechanisms for cardiovascular stem cell apoptosis and growth in the hearts with atherosclerotic coronary disease and ischemic heart failure. Ann NY Acad Sci 1010: 687-697, 2003.

7. Frangogiannis NG, Smith CW and Entman ML: The inflammatory response in myocardial infarction. Cardiovasc Res 53: 31-47, 2002.

8. Logue SE, Gustafsson AB, Samali A and Gottlieb RA: Ischemia/ reperfusion injury at the intersection with cell death. J Mol Cell Cardiol 38: 21-33, 2005

9. Quideau S, Deffieux D, Douat-Casassus C and Pouységu L: Plant polyphenols: Chemical properties, biological activities, and synthesis. Angew Chem Int Ed Engl 50: 586-621, 2011.

10. Kang NJ, Shin SH, Lee HJ and Lee KW: Polyphenols as small molecular inhibitors of signaling cascades in carcinogenesis. Pharmacol Ther 130: 310-324, 2011.

11. Marín L, Miguélez EM, Villar CJ and Lombó F: Bioavailability of dietary polyphenols and gut microbiota metabolism: Antimicrobial properties. BioMed Res Int 2015: 905215, 2015.

12. Habtemariam S and Varghese GK: The antidiabetic therapeutic potential of dietary polyphenols. Curr Pharm Biotechnol 15: 391-400, 2014.

13. Collins AR: Assays for oxidative stress and antioxidant status: Applications to research into the biological effectiveness of polyphenols. Am J Clin Nutr 81 (Suppl 1): 261S-267S, 2005.

14. Wu N, Zu Y, Fu Y, Kong Y, Zhao J, Li X, Li J, Wink M and Efferth T: Antioxidant activities and xanthine oxidase inhibitory effects of extracts and main polyphenolic compounds obtained from Geranium sibiricum L. J Agric Food Chem 58: 4737-4743, 2010.

15. Londhe JS, Devasagayam TP, Foo LY, Shastry $P$ and Ghaskadbi SS: Geraniin and amariin, ellagitannins from Phyllanthus amarus, protect liver cells against ethanol induced cytotoxicity. Fitoterapia 83: 1562-1568, 2012

16. Kang KA, Lee IK, Zhang R, Piao MJ, Kim KC, Kim SY, Shin T, Kim BJ, Lee NH and Hyun JW: Radioprotective effect of geraniin via the inhibition of apoptosis triggered by $\gamma$-radiation-induced oxidative stress. Cell Biol Toxicol 27: 83-94, 2011.

17. Liu X, Li J, Peng X, Lv B, Wang P, Zhao X and Yu B: Geraniin inhibits LPS-induced THP-1 macrophages switching to $\mathrm{M} 1$ phenotype via SOCS1/NF- $\mathrm{BB}$ pathway. Inflammation 39 : 1421-1433, 2016.

18. Zhang F, Cui J, Lv B and Yu B: Nicorandil protects mesenchymal stem cells against hypoxia and serum deprivation-induced apoptosis. Int J Mol Med 36: 415-423, 2015.

19. Zhang LL, Liu JJ, Liu F, Liu WH, Wang YS, Zhu B and Yu B: MiR-499 induces cardiac differentiation of rat mesenchymal stem cells through wnt/ $\beta$-catenin signaling pathway. Biochem Biophys Res Commun 420: 875-881, 2012.

20. Wang XY, Fan XS, Cai L, Liu S, Cong XF and Chen X: Lysophosphatidic acid rescues bone mesenchymal stem cells from hydrogen peroxide-induced apoptosis. Apoptosis 20: 273-284, 2015.

21. Zhou H, Li D, Shi C, Xin T, Yang J, Zhou Y, Hu S, Tian F, Wang J and Chen Y: Effects of exendin-4 on bone marrow mesenchymal stem cell proliferation, migration and apoptosis in vitro. Sci Rep 5: 12898, 2015.

22. Maryanovich M and Gross A: A ROS rheostat for cell fate regulation. Trends Cell Biol 23: 129-134, 2013.

23. Johnson DT, Harris RA, Blair PV and Balaban RS: Functional consequences of mitochondrial proteome heterogeneity. Am J Physiol Cell Physiol 292: C698-C707, 2007.

24. Brand MD, Buckingham JA, Esteves TC, Green K, Lambert AJ, Miwa S, Murphy MP, Pakay JL, Talbot DA and Echtay KS: Mitochondrial superoxide and aging: Uncoupling-protein activity and superoxide production. Biochem Soc Symp 71: 203-213, 2004

25. Wang P, Peng X, Wei ZF, Wei FY, Wang W, Ma WD, Yao LP, $\mathrm{Fu}$ YJ and $\mathrm{Zu}$ YG: Geraniin exerts cytoprotective effect against cellular oxidative stress by upregulation of Nrf2-mediated antioxidant enzyme expression via PI3K/AKT and ERK1/2 pathway. Biochim Biophys Acta 1850: 1751-1761, 2015. 
26. Gnecchi M, He H, Liang OD, Melo LG, Morello F, Mu H, Noiseux N, Zhang L, Pratt RE, Ingwall JS, et al: Paracrine action accounts for marked protection of ischemic heart by Akt-modified mesenchymal stem cells. Nat Med 11: 367-368, 2005.

27. Hare JM, Fishman JE, Gerstenblith G, DiFede Velazquez DL, Zambrano JP, Suncion VY, Tracy M, Ghersin E, Johnston PV, Brinker JA, et al: Comparison of allogeneic vs autologous bone marrow-derived mesenchymal stem cells delivered by transendocardial injection in patients with ischemic cardiomyopathy: The POSEIDON randomized trial. JAMA 308: 2369-2379, 2012.

28. Amado LC, Schuleri KH, Saliaris AP, Boyle AJ, Helm R, Oskouei B, Centola M, Eneboe V, Young R, Lima JA, et al: Multimodality noninvasive imaging demonstrates in vivo cardiac regeneration after mesenchymal stem cell therapy. J Am Coll Cardiol 48: 2116-2124, 2006.

29. Toma C, Pittenger MF, Cahill KS, Byrne BJ and Kessler PD: Human mesenchymal stem cells differentiate to a cardiomyocyte phenotype in the adult murine heart. Circulation 105: 93-98, 2002.

30. Urao N and Ushio-Fukai M: Redox regulation of stem/progenitor cells and bone marrow niche. Free Radic Biol Med 54: 26-39, 2013.

31. Gechev TS and Hille J: Hydrogen peroxide as a signal controlling plant programmed cell death. J Cell Biol 168: 17-20, 2005.

32. Fitzpatrick DF, Hirschfield SL and Coffey RG: Endothelium-dependent vasorelaxing activity of wine and other grape products. Am J Physiol 265: H774-H778, 1993.

33. Sheng R, Gu ZL, Xie ML, Zhou WX and Guo CY: EGCG inhibits cardiomyocyte apoptosis in pressure overload-induced cardiac hypertrophy and protects cardiomyocytes from oxidative stress in rats. Acta Pharmacol Sin 28: 191-201, 2007.

34. Sangeetha P, Das UN, Koratkar R and Suryaprabha P: Increase in free radical generation and lipid peroxidation following chemotherapy in patients with cancer. Free Radic Biol Med 8: 15-19, 1990.
35. Andón FT and Fadeel B: Programmed cell death: Molecular mechanisms and implications for safety assessment of nanomaterials. Acc Chem Res 46: 733-742, 2013.

36. Garrido C, Galluzzi L, Brunet M, Puig PE, Didelot C and Kroemer G: Mechanisms of cytochrome c release from mitochondria. Cell Death Differ 13: 1423-1433, 2006.

37. Gnecchi M, He H, Melo LG, Noiseaux N, Morello F, de Boer RA, Zhang L, Pratt RE, Dzau VJ and Ingwall JS: Early beneficial effects of bone marrow-derived mesenchymal stem cells overexpressing Akt on cardiac metabolism after myocardial infarction. Stem Cells 27: 971-979, 2009.

38. Zhai JW, Gao C, Ma WD, Wang W, Yao LP, Xia XX, Luo M, $\mathrm{Zu} \mathrm{YG}$ and $\mathrm{Fu}$ YJ: Geraniin induces apoptosis of human breast cancer cells MCF-7 via ROS-mediated stimulation of p38 MAPK. Toxicol Mech Methods 26: 311-318, 2016.

39. Zaruba MM, Theiss HD, Vallaster M, Mehl U, Brunner S, David R, Fischer R, Krieg L, Hirsch E, Huber B, et al: Synergy between CD26/DPP-IV inhibition and G-CSF improves cardiac function after acute myocardial infarction. Cell Stem Cell 4: 313-323, 2009.

40. Ping YF, Yao XH, Jiang JY, Zhao LT, Yu SC, Jiang T, Lin MC, Chen JH, Wang B, Zhang R, et al: The chemokine CXCL12 and its receptor CXCR4 promote glioma stem cell-mediated VEGF production and tumour angiogenesis via PI3K/AKT signalling. J Pathol 224: 344-354, 2011.

This work is licensed under a Creative Commons Attribution-NonCommercial-NoDerivatives 4.0 International (CC BY-NC-ND 4.0) License. 